\title{
Gene, Stem Cell, and Alternative Therapies for SCA 1
}

\author{
Jacob L. Wagner, Deirdre M. O'Connor, Anthony Donsante and Nicholas M. Boulis*
}

Boulis Laboratory, Department of Neurosurgery, Emory School of Medicine, Atlanta, GA, USA

Spinocerebellar ataxia 1 is an autosomal dominant disease characterized by neurodegeneration and motor dysfunction. In disease pathogenesis, polyglutamine expansion within Ataxin-1, a gene involved in transcriptional repression, causes protein nuclear inclusions to form. Most notably, neuronal dysfunction presents in Purkinje cells. However, the effect of mutant Ataxin-1 is not entirely understood. Two mouse models are employed to represent spinocerebellar ataxia 1, a B05 transgenic model that specifically expresses mutant Ataxin-1 in Purkinje cells, and a Sca1 154Q/2Q model that inserts the polyglutamine expansion into the mouse Ataxin-1 locus so that the mutant Ataxin-1 is expressed in all cells that express Ataxin-1. This review aims to summarize and evaluate the wide variety of therapies proposed for spinocerebellar ataxia 1, specifically gene and stem cell therapies.

Keywords: SCA 1, gene therapy, stem cell therapy, mouse model, Ataxin-1, RNAi

\section{OPEN ACCESS}

Edited by:

George Smith,

Temple University School of Medicine,

USA

Reviewed by:

Christian Gonzalez-Billault,

University of Chile, Chile

Michele Papa,

Seconda Università degli Studi di

Napoli, Italy

${ }^{*}$ Correspondence:

Nicholas M. Boulis

nboulis@emory.edu

Received: 12 May 2016

Accepted: 26 July 2016

Published: 12 August 2016

Citation:

Wagner JL, O'Connor DM, Donsante A and Boulis NM (2016) Gene, Stem Cell, and Alternative Therapies for SCA 1.

Front. Mol. Neurosci. 9:67. doi: 10.3389/fnmol.2016.00067

\section{INTRODUCTION}

Spinocerebellar ataxia (SCA) is a group of autosomal dominant neurodegenerative diseases characterized by progressive degeneration in the spinal cord, brain stem, and cerebellum. SCA types 1-36 have been identified, each attributable to a different gene. SCA genetic abnormalities are most commonly caused by cytosine-adenosine-guanine (CAG) repeat expansion leading to a polyglutamine expanded protein product presumed to be toxic to neurons (Whaley et al., 2011; Table 1).

In spinocerebellar ataxia 1 (SCA 1), the accumulation of the mutant ataxin-1 protein (ATXN1) causes loss of cerebellar Purkinje cells (PC) and dysfunction and degeneration in the cerebellum, brain stem, and spinal cord. To date, treatment consists of managing the symptoms with pharmacologic agents. No fundamental therapies for SCA 1 have been identified yet (Whaley et al., 2011), although several experimental studies have shown promising results.

This review will provide background information on SCA 1 and the mouse models used as well as inform the reader about promising gene and stem cell therapy approaches. Challenges regarding these novel approaches will be discussed and other alternative therapies will be briefly reviewed.

\section{FACTS AND DEMOGRAPHICS}

According to the National Ataxia Foundation, approximately 1-2 in 100,000 people will develop SCA 1, but the frequency varies depending on ethnic background and location (National Ataxia Foundation, https://www.ataxia.org/).

The onset of the disease begins around the 3rd-4th decade but can develop between the ages of 4 and 74 (Schols et al., 2004). From onset, patient survival ranges from 10 to 28 years (average $=15$ years; Jayadev and Bird, 2013). In cases of early onset (before 13 years old), disease progression 
TABLE 1 | Autosomal dominant hereditary ataxias.

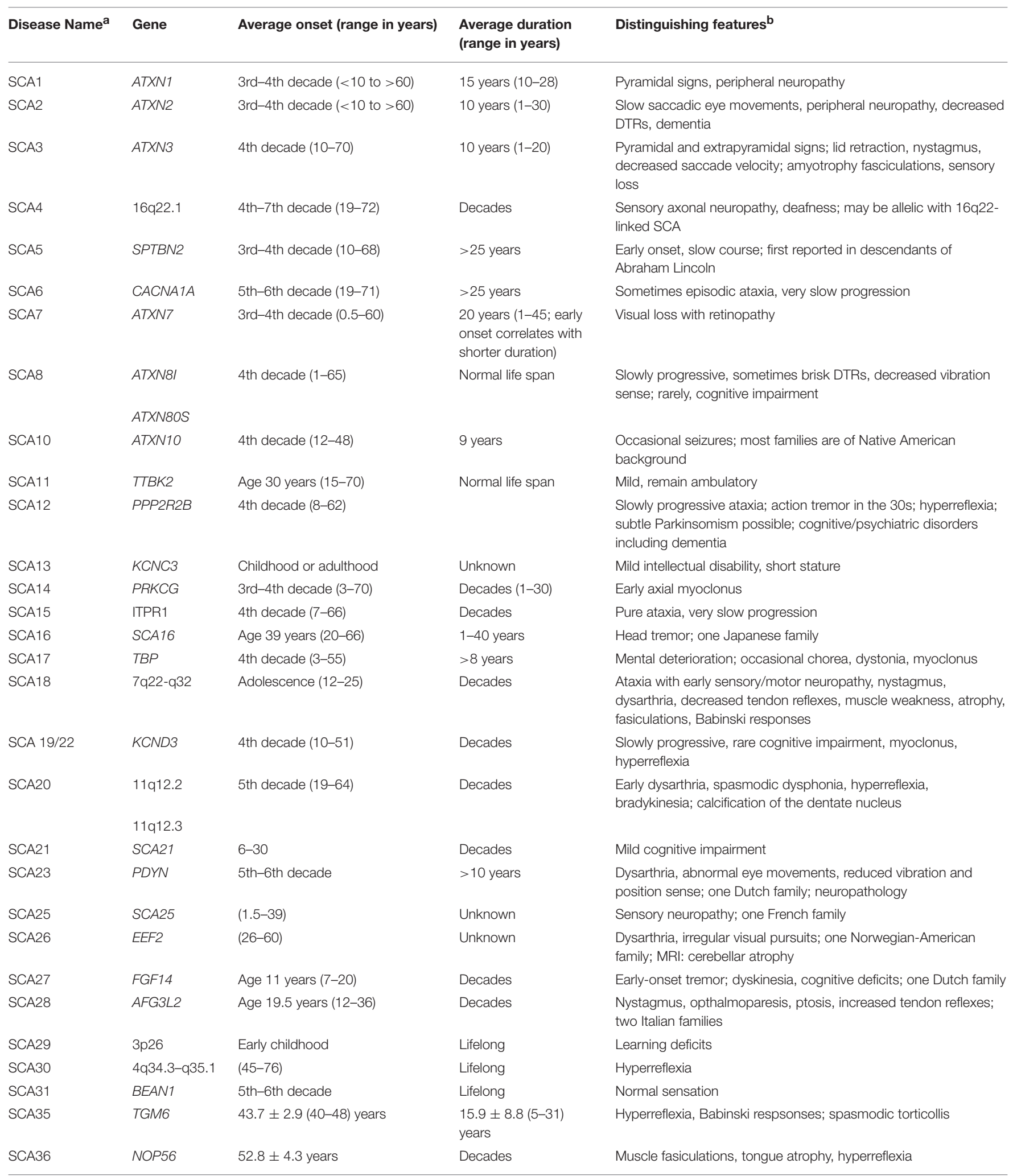

DTR, deep tendon reflex.

a SCA9 has not been assigned.

${ }^{b}$ All have gait ataxia.

Reprinted by permission from Macmillan Publishers Ltd: Genetics in Medicine (Jayadev and Bird, 2013), copyright (2013). 
is more rapid and severe, with patients usually dying before the age of 16 (Zoghbi et al., 1988).

Clinically, SCA 1 symptoms include limb ataxia, gait disturbance, slurred speech, balance difficulty, brisk tendon reflexes, hypermetric saccades, nystagmus, mild dysphagia, and cognitive impairment. SCA 1 symptoms can be distinguished from other hereditary ataxias by the predominance of pyramidal symptoms. Amyotrophy and sensory loss can also be present in affected individuals. Olivopontocerebellar atrophy is the major finding on MRI/CT (Schols et al., 2004). Eventually, affected individuals develop respiratory failure, the main cause of death for SCA 1 (Subramony and Ashizawa, 1993).

\section{MOLECULAR PATHOGENESIS}

SCA 1 is caused by a CAG repeat expansion in the ATXN1 gene (OMIM: 601556) that encodes ATXN1. In normal ATXN1, the triplet CAG is repeated 6 to 36 times while in mutant forms (polyQ-ATXN1) the number of repeats can exceed 100. Similar to other polyglutamine (polyQ) diseases such as Huntington's, as the polyQ expansion becomes longer, disease onset occurs earlier, and the symptoms are more severe (Kang and Hong, 2009). The polyQ expansion is thought to be due to errors in the DNA replication machinery (Kang et al., 1995). The number of repeats can increase from generation to generation, particularly in the paternal germline (Matilla et al., 1993).

ATXN1 is mainly localized to the nucleus of neuronal cells; however, in Purkinje cells, it is found in both the cytoplasm and the nucleus (Servadio et al., 1995). It associates with a collection of high molecular weight protein complexes that also contain Capicua (CIC), a transcriptional repressor containing a high mobility group (HMG) box. The presence of human polyQ-ATXN1 alters the size distribution of these complexes and inhibits the repressor activity of CIC. Overexpression of CIC in a fly model suppresses the morphologic changed induced by polyQ-ATXN1 (Lam et al., 2006). Additionally, Yue et al. found that ATXN1 binds RNA and that, as size of its polyQ tract increases, its ability to bind RNA decreases. Thus, expansion of the ATXN1 polyQ tract may alter its role in RNA metabolism (Yue et al., 2001). polyQ-ATXN1 aggregates and forms inclusions in the nucleus and cytoplasm of neurons, especially in PCs (Kang and Hong, 2009). PolyQ-ATXN1 alters several cellular pathways, including transcription (Cvetanovic et al., 2007; Lee S. et al., 2008), RNA processing (Hong et al., 2003), and signal transduction (Goold et al., 2007; Gatchel et al., 2008), disrupting normal cell function and leading to cell death (Kang and Hong, 2009).

Phosphorylation contributes to the regulation of ATXN1 folding and distribution. Emamian et al. found that serine 776 (S776) was phosphorylated in transgenic mice carrying ATXN1. Mutating S776 to alanine altered the intracellular deposition of polyQ-ATXN1, preventing nuclear inclusions from forming. When the S776 and A776 forms of polyQ-ATXN1 (polyQ-ATXN1-S776 and polyQ-ATXN1-A776, respectively) were expressed in Purkinje cells in mice, polyQ-ATXN1A776 was substantially less toxic than polyQ-ATXN1-S776, demonstrating that phosphorylation of this serine residue contributes significantly to the harmful effects of the mutant protein (Emamian et al., 2003). The protective effect of A776 appears to be due to the fact that polyQ-ATXN1-A776 does not produce the abnormal, high molecular weight complexes that are observed in mice carrying polyQ-ATXN1-S776, even though both forms associated strongly with CIC. Interestingly, it appears that toxicity arises, not due to novel interactions between polyQ-ATXN1 and other proteins, but from polyQATXN1 adversely affecting the function of proteins it normally interacts with (Lam et al., 2006). Protein Kinase A (PKA) is the cAMP-dependent kinase responsible for S776 of ATXN1 (Chen et al., 2003; Jorgensen et al., 2009). In addition to S776, VierraGreen et al. found through matrix-assisted laser description ionization time-of-flight mass spectrometry (MALDI TOF) and mutational analysis that S239 is also a phosphorylation site of ATXN1 (Vierra-Green et al., 2005), although further research is required to determine if $\mathrm{S} 239$ is linked to SCA 1 pathogenesis. Understanding the phosphorylation of ATXN1 allows for a better understanding of the role ATXN1 has within neurons, specifically with post-translational modifications, which is vital for future therapeutic strategies.

Relevant to polyQ-ATXN1 cytotoxicity, Lee et al. found that ATXN1 levels might be post-transcriptionally regulated by miRNA, specifically miR-19, miR-101, and miR-130. When miR-19, miR101, and miR130 were transfected into HEK293T, HeLa and MCF7 cells, a marked decrease in ATXN1 levels was observed. When $2^{\prime}$-O-methyl inhibitors against the miRNA were added to HEK293T cells, ATXN1 levels increased. These findings present the possibility that miRNA-binding site mutations or miRNA genes might lead to the SCA 1 neurodegenerative phenotypes (Lee Y. et al., 2008).

\section{MOUSE MODELS}

Mouse models have been generated to study the cerebellar degeneration associated with SCA 1. In the B05 transgenic mouse model (B05) the human SCA $1 \mathrm{cDNA}$ was modified to contain $82 \mathrm{CAG}$ repeats and expressed under the control of the Purkinje cell protein 2 (pcp2) promoter to form a pcp2/SCA1 transgene. The $5^{\prime}$ regulatory sequences of $p c p 2$ are sufficient to restrict transgene expression to PCs (Oberdick et al., 1990; Vandaele et al., 1991). B05 transgenic mice overexpress polyQATXN1, which leads to the loss of PCs from the cerebellum and thus present the neurological phenotype of ataxia. Abnormalities include reduced activity, head swaying and incoordination. Ataxia onset begins at 12 weeks of life. However, because the mutant cDNA is only expressed in Purkinje cells, this model only displays symptoms of degenerating PCs and these mice have a normal life span (Burright et al., 1995). Patients, in contrast, experience dysfunction in a variety of neurons in addition to PCs (Bürk et al., 2001). These other neurons produce cognitive dysfunction that is not represented in the B05 mouse model (Table 2), which makes comparisons to SCA 1 patients difficult.

To better model SCA 1, Watase et al. generated a SCA 1 knock-in model by introducing a 154-CAG expansion into exon 8 of the endogenous ATXN 1 locus. The knock-in mouse model, called Sca1 154Q/2Q (154Q/2Q), expresses polyQ-ATXN1 in neurons in the cortex, thalamus, hypocampus, caudate nucleus, 
putamen, brain stem, cerebellum, and spinal cord. With polyQATXN1 allele present throughout the central nervous system, the $154 \mathrm{Q} / 2 \mathrm{Q}$ model displays more of the human disease features, such as motor incoordination, muscle wasting, cognitive impairment, and premature death, making it a more relevant physiological model of the disease. Disease onset begins at 7-8 weeks and mice die prematurely at 35-45 weeks of age (Watase et al., 2002; Table 2).

No non-rodent animal model exists for SCA 1. A transgenic model of Huntington's disease, another polyQ disease involving an expanded polyglutamine repeat in HTT, exists in rhesus macaque (Yang et al., 2008), suggesting that a SCA 1 model could be made as well.

\section{GENE THERAPY}

SCA 1 is a monogenic disease; thus, gene therapy is an obvious treatment approach. Gene therapeutic intervention involves either reducing expression of the mutant ATXN1 through gene silencing or overexpressing a paralog of ATXN1, ataxin-1like (ATXN1L), to competitively inhibit the formation of toxic complexes by polyQ-ATXN1 (Keiser et al., 2013).

The RNAi approach regulates gene expression through small RNAs, including artificial microRNA (miRNA), small interfering RNA (siRNA), and short hairpin RNA (shRNA). Short hairpin RNA, siRNA, and miRNA are all non-coding RNA that post-transcriptionally regulate mRNA transcript levels. siRNA acts on a particular sequence for degradation while miRNA is more likely to target mRNA for transcriptional silencing (Lam et al., 2015). Unlike siRNA which requires two independent RNA strands, a sense and antisense strand that guides the RNA-induced silencing complex (RISC), shRNA is a single strand that folds back on itself to produce a doublestranded molecule (Davidson and Paulson, 2004). The Davidson research group showed that RNAi platforms (Keiser et al., 2013) expressed using viral vectors could potentially have therapeutic effects on polyglutamine diseases. Xia et al. investigated the possibility that virally expressed siRNA could decrease levels of polyglutamine expanded proteins in neural PC12 clonal cells. The lines were developed to express tetracycline-repressible eGFP-polyglutamine fusion proteins, which the siRNA targeted.
Decrease in protein aggregate levels was shown by western blot analysis and cellular fluorescence (Xia et al., 2002; Table 3).

RNA interference (RNAi) has already been proven to be effective in a number of diseases caused by CAG repeat expansion. Harper et al. injected AAV2/1 targeting huntingtin (HTT) intracranially and found reduced HTT mRNA levels and protein expression in HTT transgenic mice. Mice showed improved behavioral outcomes and reduced neuropathic HTT abnormalities (Harper et al., 2005). Additionally, Monteys et al. found preferential silencing of the mutant HTT allele in vitro by miRNA. Preferential knockdown of the mutant allele was achieved in vivo when one of the miRNAs tested was delivered through AAV2 by striatal bilateral injection into HTT double transgenic mice, However, knockdown of the wild-type allele was also detected (Monteys et al., 2015). Miller et al. generated siRNA that silences the SCA 3-associated allele, ataxin-3 (ATXN3), targeting an adjacent single nucleotide polymorphism (SNP). In vitro, the RNAi approach successfully silenced both plasmid and viral expression of ATXN3 (Miller et al., 2003). In vivo, AAV2 vector was delivered via intracerebellar injection into SCA 3 mice. Rodriguez-Lebron et al. found that anti-ATXN3 miRNA suppressed ATXN3 expression and cleared nuclear accumulation of mutant ATXN3 (RodriguezLebron et al., 2013). Lastly, for SCA 7, Ramachandran et al. found more than $50 \%$ reduction of mutant human and wildtype mouse ATXN7 allele after AAV2/1 subretinal space injection of miRNA into SCA 7 transgenic mice. Mice preserved normal retinal function after injection (Ramachandran et al., 2014). Keiser et al. found that ATXN1 levels can be reduced $30 \%$ by miS1 knockdown through AAV1 deep cerebellar nuclei injection in an adult rhesus. The intervention was well tolerated and there were no clinical complications. The biodistribution and tolerability of the miS1 treatment supports its use as a clinical therapeutic (Keiser et al., 2015; Table 3).

Xia et al. tested shRNA to target the Sca 1 locus. They generated AAV serotype 2/1 (AAV 2/1) that expressed shRNA which was delivered via intracerebellar injection. This treatment resolved ATXN1 nuclear inclusions and PC morphology as well as improving motor coordination in transgenic B05 mice

TABLE 2 | Overview of mouse models for SCA 1.

\begin{tabular}{|c|c|c|}
\hline & B05 transgenic mice (B05) & Sca1 154Q/2Q mice (154Q/2Q) \\
\hline Phenotype & Motor incoordination, ataxia (12 weeks), no cognitive impairment & $\begin{array}{l}\text { motor incoordination, muscle wasting, cognitive impairment, memory } \\
\text { deficits }\end{array}$ \\
\hline Physical Onset & 5 weeks & 7-8 weeks \\
\hline Course of the disease & Normal life span & Premature, 35-45 weeks \\
\hline \multirow[t]{3}{*}{ Neuropathology } & $\begin{array}{l}\text { PC loss, Bergmann glial proliferation, shrinkage and gliosis of molecular } \\
\text { layer }\end{array}$ & Reduced dendritic arborization of PCs (early stage) \\
\hline & & Neuronal intranuclear inclusions and PC loss (advanced disease) \\
\hline & Purkinje neuron dendritic and somatic atrophy & Hypocampal synaptic dysfunction but no significant loss \\
\hline Mechanism & $\begin{array}{l}\text { Overexpression of polyQ-ATXN1 ( } 82 \text { CAG repeats) under the control of } \\
\text { Purkinje Cell pcp2 promoter }\end{array}$ & $\begin{array}{l}\text { Expanded repeat of } 154 \text { CAGs was inserted into the mouse Sca } 1 \text { locus } \\
\text { (knock-in) }\end{array}$ \\
\hline References & Burright et al., 1995; Clark et al., 1997 & Watase et al., 2002 \\
\hline
\end{tabular}


TABLE 3 | Overview of gene therapies for SCA 1.

\begin{tabular}{|c|c|c|c|c|}
\hline & Treatment/vector & Animal model & Route & Outcome \\
\hline \multirow[t]{2}{*}{ Keiser et al., 2013} & (1) miRNA/AAV serotype 2/1 & B05 mice & DCN injection & Widespread PC transduction \\
\hline & (2) Atxn1 Like/AAV serotype 2/1 & & & $\begin{array}{l}\text { Improved histology and } \\
\text { behavioral profiles }\end{array}$ \\
\hline Xia et al., 2004 & siRNA/AAV2 & B05 mice & $\begin{array}{l}\text { Direct injection into the cerebellar } \\
\text { lobules }\end{array}$ & $\begin{array}{l}\text { Cerebellar morphology } \\
\text { restoration, PC inclusions } \\
\text { resolution, improved motor } \\
\text { coordination }\end{array}$ \\
\hline Keiser et al., 2014 & RNAi/AAV serotype 2/5 & SCA1 154Q/2Q knock-in mice & Deep cerebellar nuclei (DCN) & $\begin{array}{l}\text { Preserved neurohistology and } \\
\text { rotarod performance }\end{array}$ \\
\hline \multirow[t]{2}{*}{ Venkatraman et al., 2014} & HDAC 3 depletion & $\begin{array}{l}\text { (1) PC-specific HDAC3 null } \\
\text { knock-in mice }\end{array}$ & $\mathrm{N} / \mathrm{A}$ & $\begin{array}{l}\text { (1) No improvement in cognitive } \\
\text { and cerebellar function }\end{array}$ \\
\hline & & $\begin{array}{l}\text { (2) SCA1 154Q/2Q mice } \\
\text { (heterozygous HDAC3+/- mice) }\end{array}$ & & $\begin{array}{l}\text { (2) Deleterious effects both } \\
\text { behaviorally and histologically }\end{array}$ \\
\hline
\end{tabular}

(Xia et al., 2004). Keiser et al. tested the therapeutic utility of SCA 1-targeted AAV 2/1 miRNA to suppress ATXN1 expression. The construct was delivered via deep cerebellar nuclei injection and resulted in PC transduction and improved gait and balance in transgenic B05 mice (Keiser et al., 2013). To our knowledge, siRNA or shRNA targeting ATXN1 has not been evaluated in $154 \mathrm{Q} / 2 \mathrm{Q}$ mice. Keiser et al. found that miRNA therapy in $154 \mathrm{Q} / 2 \mathrm{Q}$ mice was sufficient to reduce SCA 1 symptoms. They tested the efficacy of miRNA delivered via AAV 2/5 to the deep cerebellar nuclei. The RNAi inhibited SCA 1-related transcriptional changes, preserved the cerebellar lobule, and improved motor coordination (Keiser et al., 2014; Table 3).

The potential toxicity of small RNA should be noted. Grimm et al. studied the long-term effect of high shRNA expression in the livers of mice through AAV8 intravenous infusion. Of the $49 \mathrm{AAV} / \mathrm{shRNA}$ vectors tested, 36 caused does-dependent liver injury, with 23 of those leading to death. Grimm et al. found the morbidity to be associated with downregulation of miRNAs derived from the liver, possibly indicating competition with the shRNAs (Grimm et al., 2006). The study demonstrates the risk of oversaturating small RNA pathways with RNAi therapy.

As an alternate approach to RNAi, overexpression of the ATXN1L protein also represents a feasible therapy for SCA 1. ATXN1 and ATXN1L interact with a similar set of proteins, including $\mathrm{CIC}$, through their ATXN1 and HMG-box protein 1 domain (AXH domain). Overexpression of ATXN1L could outcompete polyQ-ATXN1 for binding to CIC, reducing the amount of toxic complexes and disease severity (de Chiara et al., 2003; Lam et al., 2006; Bowman et al., 2007; Lim et al., 2008). Keiser et al. showed that overexpression of ATXN1L from an AAV2/1 vector has protective effects in B05 mice. In their study, human ATXN1L was expressed using AAV 2/1 and was delivered into the deep cerebellar nuclei. Mice receiving the injection exhibited improved gait, agility, and hind limb musculature and also decreased nuclear inclusions and PC loss, similar to that observed with the miRNA. Keiser et al. concludes that both overexpression of ATXN1L and RNAi are potentially viable treatment options for SCA 1 patients (Keiser et al., 2013; Table 3).

Alternatives to targeting the gene directly through RNAi and ATXN1L include histone deacetylase transcriptional repression. ATXN1 binds $\mathrm{HDAC} 3$, a class 1 histone deacetylase (HDAC) required for ATXN1 induced transcriptional repression (Karagianni and Wong, 2007). Venkatraman et al. tested the effect of PC-specific HDAC3 depletion in 154Q/2Q mice by siRNA knock down. However, mice did not show improvement in cerebellar or cognitive function. Additionally, Venkatraman et al. crossed a floxed HDAC3 mouse line with a mouse driving Cre expression from a $p c p-2$ promoter. The $p c p-2$ promoter turns on 6 days after birth in PC cells and reaches a maximum by $2-3$ weeks after birth, which is about the time that transcriptional problems manifest (Lin et al., 2000; Gatchel et al., 2008). The offspring line has a conditional complete loss of HDAC3 in PCs and demonstrated dramatic PC degeneration and early onset ataxia. These results warn of the risk of neurotoxic side effects that can be caused by altering HDAC3 expression to treat SCA 1 (Venkatraman et al., 2014; Table 3).

In our opinion of the gene therapies, RNAi knockdown treats the cause of the disease while ATXN1L might not, as the polyQATXN1 aggregates are still present. On the other hand, this cannot be definitive known until a side by side comparison between ATXN1L and RNAi with stringent control of the conditions is performed. Additionally, the issue of small RNA oversaturation arises. As with most gene therapies, the question also remains, is there adequate transduction of the therapeutic into the affected cells?

\section{STEM CELL THERAPY}

Stem-cell-based therapies represent a new strategy for spinocerebellar ataxias. Neurotransplantation has been performed in various cerebellar mutant mice using different types of cells and delivery techniques to stop PC degeneration and restore normal cerebellar architecture. Currently, a few studies have tried stem cell transplantation in SCA 1 mouse models and showed positive results both functionally and histologically.

An interesting approach by Chen et al. combines stem cell and gene therapy for gene delivery in SCA 1 mice. Bone marrow-derived cells (BMDCs) can fuse in vivo with somatic 
cells, including Purkinje neurons (Alvarez-Dolado et al., 2003; Weimann et al., 2003). Bone marrow derived cells (BMDC) were genetically modified using AAV7 to carry two SCA 1 modifier genes, DnaJB4 and Pcbp3. The genes were determined by Fernandez-Funez et al. to have attenuating effects on SCA 1 onset by assisting chaperone activity and transcription stabilization, respectively (Fernandez-Funez et al., 2000). Chen et al. delivered BMDC by a retroorbital sinus injection into 154Q/2Q mice. PC and BMDC fused to produce heterokaryons with PC properties. In the treated 154Q/2Q mice, there was some improvement in pathology. Mice showed a diminished number of nuclear inclusions and an increased number of surviving PC, highlighting the potential neuroprotective effects of this combined strategy (Chen et al., 2011; Table 4).

Chintawar et al. transplanted neural precursor cells (NPCs) from the subventricular zone of adult mice to cerebellar white matter of B05 mice. Mice received injections into three separate sites of the cerebellar white matter at 5-, 13-, or 24-weeks-old time points where cerebellar pathology is not yet observed, PC loss begins, and PC are mostly abnormal, respectively. Grafted NPCs only migrated to the cerebellar cortex in 24-week-old mice. Additionally, motor skills only improved in mice treated at 24 weeks when compared to shams. When grafted NPCs did migrate to the cerebellar cortex, grafts did not adopt PC characteristics, but NPC-grafted B05 mice did exhibit thicker molecular layer and diminished PC loss (Chintawar et al., 2009; Table 4).

Matsuura et al. found that intrathecal injection of mesenchymal stem cells (MSCs) into the meningeal covering of the cerebellum improved PC organization in B05 mice injected at 5 weeks of age. At 24 weeks of age, untreated B05 mice displayed multilayered PC as a result of ectopically located PC bodies, but mice of the same age injected with MSCs had monolayered PCs. Additionally, MSC treatment reduced PC dendrite atrophy and normalized behavior and motor deficits (Matsuura et al., 2014; Table 4).

Stem cell therapies on non-SCA 1 mouse models are relevant to mention. In Lercher mutant mice, a mouse model characterized by the selective early post-natal death of PCs in the cerebellum, Jones et al. found that bone marrow-derived mesenchymal stem cells injected into the cerebellum migrated throughout the cerebellum. Their results showed an increase in the number of surviving PCs due to the neurotrophic factors released by adjacent grafted cells as well as an improvement in motor function (Jones et al., 2010).

Stem cell therapy in SCA 2 mice has also proven successful. Human MSC were delivered intravenously at 12, 23, 33, and 42 weeks of age (disease onset for untreated mice was 33-40 weeks of age). The injections resulted in a delay in the onset of motor function deterioration. In the same study, human MSC were injected into the cerebellum through the foramen magnum both before and after motor function loss but, unlike the intravenous route, there was no improvement (Chang et al., 2011).

Two clinical trials have looked at the safety and efficacy of stem cell transplantation in SCA. In a phase I/II trial, Jin et al. intrathecally and intravenously infused human umbilical cord mesenchymal stem cells (UC-MSC) into 16 patients with genetically diagnosed SCA 1, 2, or 3. Results showed that no serious transplantation side effects occurred during the 12 month follow-up period. Berg Balance Scale (BBS) and International Cooperative Ataxia Rating Scale (ICARS) scores improved for at least 6 months following the transplantation. Results were scored by a blinded neurologist (Jin et al., 2013) (NCT01360164).

Dongmei et al. also studied the effect of intrathecal injection of umbilical cord mesenchymal stem cells (UC-MSC) in 14 patients with SCA. The types of SCA were not specified. Serial weekly injection, with four injections total, significantly improved Activity of Daily Living Scale (ADL), and ICARS scores. ICARS and ADL scores decreased significantly 1 month after treatment. For follow-up, 8 patients remained stable for an average period of 9 month and 6 progressed after treatment with average stabilization of 4 months (Dongmei et al., 2011).

These studies may represent a proof of principle of the therapeutic potential of stem cells in SCA. However, both trials were open label, and substantial placebo effects cannot be discounted. Further clinical studies including more patients need to be performed in order to better assess safety and efficacy.

\section{ALTERNATIVE THERAPIES}

While gene and stem cell therapies are currently most prominent, many alternative therapies, including protein delivery, are also potentially relevant treatments for SCA 1. Main approaches

TABLE 4 | Overview of stem cell therapies for SCA 1.

\begin{tabular}{|c|c|c|c|c|c|}
\hline & Mouse model & Type of stem cells & Route & Histology results & Functional results \\
\hline Chen et al., 2011 & SCA1 154Q/2Q mice & $\begin{array}{l}\text { BMDC (genetically } \\
\text { modified using AAV7 to } \\
\text { carry SCA } 1 \text { modifier } \\
\text { genes) }\end{array}$ & $\begin{array}{l}\text { Right retro-orbital sinus } \\
\text { injection }\end{array}$ & $\begin{array}{l}\text { Diminished nuclear } \\
\text { inclusions, increased } \\
\text { number of surviving PC }\end{array}$ & Not assessed \\
\hline \multirow[t]{2}{*}{ Chintawar et al., 2009} & B05 transgenic mice & $\begin{array}{l}\text { Subventricular zone } \\
\text { derived NPCs }\end{array}$ & $\begin{array}{l}\text { Stereotactic cerebellar } \\
\text { white matter microinjection }\end{array}$ & Thicker molecular layer. & Improved motor skills \\
\hline & & & & Diminished PC loss & Normalized behavior \\
\hline \multirow[t]{2}{*}{ Matsuura et al., 2014} & B05 transgenic mice & Bone marrow derived MSC & Intrathecal injections & $\begin{array}{l}\text { Suppression of PC } \\
\text { dendrites atrophy }\end{array}$ & $\begin{array}{l}\text { Improved motor } \\
\text { coordination }\end{array}$ \\
\hline & & & & Thicker molecular layer & \\
\hline
\end{tabular}


include vascular endothelial growth factor (VEGF), cAMPdependent protein kinase A (PKA) inhibitory polypeptide, and 3,4-diaminopyridine.

Cvetanovic et al. found that vascular endothelial growth factor (VEGF) improves the SCA 1 phenotype in $154 \mathrm{Q} / 2 \mathrm{Q}$ mice. VEGF is an angiogenic and neurotrophic factor, and it is down-regulated in SCA 1 mice. Cvetanovic et al. crossed 154Q/2Q mice with transgenic mice that overexpress VEGF. These mice exhibited thicker molecular layers and improved motor performance. This study went further to show the positive effect that recombinant VEGF has on 154Q/2Q mice. As it cannot cross the blood brain barrier (BBB), an intracerebroventricular osmotic pump was inserted subcutaneously into 11-week-old mice to deliver VEGF via a catheter into the right lateral ventricle over 2 weeks. Mice with the pump exhibited thicker molecular layers and improved motor performance. The authors proposed that VEGF could be a biomarker for human disease progression (Cvetanovic et al., 2011; Table 5).

PC degeneration in SCA 1 is enhanced by the phosphorylation of S776 of polyQ-ATXN1 by PKA (Chen et al., 2003; Emamian et al., 2003; Jorgensen et al., 2009). Hearst et al. (2014a) engineered a PKA inhibitory polypeptide to prevent the formation of nuclear inclusions. The PKA inhibitory polypeptide (Synb1-ELP-PKI) is composed of a cell-penetrating peptide (Synb1), a heat responsive elastin-like peptide (ELP) carrier to increase peptide half-life, and a PKA inhibitory peptide (PKI). Using B05 mice, Synb1-ELP-PKI was delivered through the intraperitoneal or intranasal injection route. Both routes allowed the peptide to successfully cross the $\mathrm{BBB}$ and localize in the cerebellum. Mice showed decreased intranuclear inclusions and improved PC morphology. Motor function was not assessed (Hearst et al., 2014a; Table 5).

Hourez et al. (2011) found that aminopyridines might have positive neuroprotective and symptomatic effects for SCA 1.3,4diaminopyridine is an organic compound that blocks potassium channels and is used to treat neuronal dysfunction (Kirsch and Narahashi, 1978). Before SCA 1 symptoms present, B05 mice show reduced PC firing rate. Acute subcutaneous injection of 3,4-diaminopyridine in young B05 mice normalized the firing rate of PCs and improved motor function. Chronic subcutaneous injection, partially prevented PC atrophy. This effect was associated with increased brain-derived neurotrophic factor (BDNF), suggesting that protection against atrophy is possibly carried out by BDNF, which occurs secondary to the return of electrical activity (Hourez et al., 2011; Table 5). Adding to the argument that aminopyridines increase PC firing frequency, (Alviña and Khodakhah, 2010) reported that 4-aminopyridine restored pacemaking precision in the PCs in a mouse model of episodic ataxia 2 (Alviña and Khodakhah, 2010). A clinical trial of 4-aminopyridine (dalfampiridine) was completed in 2014. In a crossover study 20 patients with either SCA $1,2,3$, or 6 received an oral dose of 4 -aminopyridine for 4 weeks and 4 weeks of placebo with a 2 week washout period in between. One patient had adverse effects to the drug. Results showed that 4 -aminopyridine did not significantly improve performance on the Timed 25 Feet Walking Test, the Scale of Assessment and Rating of Ataxia (SARA), or the Biomechanical Assessment of Gait-Stride Length (NCT01811706).

Other alternatives strategies that are less invasive, including whole body vibration (WBV), heat shock protein (HSP) stimulation, and oral doses of lithium, have also shown promising results and could be used alone or as an adjunct to other treatments. Kaut et al. investigated the effect of stochastic whole body vibration on SCA 1, 2, 3, and 6 patients in a double blind sham controlled study. WBV stimulates the neuromuscular system through vibration, and it has already shown to improve balance and mobility in patients with Parkinson's (Haas et al., 2006). WBV was applied on 4 sequent days, the treatment consisting of five stimulus trains of $60 \mathrm{~s}$ duration at a frequency of $6.5 \mathrm{~Hz}$ and $60 \mathrm{~s}$ resting time between stimuli. The sham group received the same treatment with a frequency of $1 \mathrm{~Hz}$. Improvements in gait, posture, and speed of speech were seen but no response in limb kinetics and ataxia of speech was observed (Kaut et al., 2014). However, it is necessary to mention a Huang

TABLE 5 | Overview of other therapies for SCA 1.

\begin{tabular}{|c|c|c|c|c|}
\hline & Treatment & Animal model & Route & Outcome \\
\hline \multirow[t]{2}{*}{$\begin{array}{l}\text { Cvetanovic et al., } \\
2011\end{array}$} & VEGF & 154Q/2Q mice & $\begin{array}{l}\text { Pharmacologic: } \\
\text { intraventricular infusion }\end{array}$ & Improved pathological hallmarks and motor function \\
\hline & & & $\begin{array}{l}\text { Transgenic: gene } \\
\text { over-expression }\end{array}$ & \\
\hline Hearst et al., 2014a & $\begin{array}{l}\text { PKA inhibitory polypeptide } \\
\text { (Synb1-ELP-PK) }\end{array}$ & B05 mice & Intraperitoneal/intranasal & Decreased intranucelar inclusions, improved PC morphology \\
\hline Hourez et al., 2011 & 3,4-diaminopyridine & B05 mice & Subcutaneous injection & $\begin{array}{l}\text { Normalized PC firing rate, reduced PC atrophy, improved } \\
\text { motor function }\end{array}$ \\
\hline Hearst et al., 2014b & $\begin{array}{l}\text { Focused Laser Light } \\
\text { Hyperthermia }\end{array}$ & B05 mice & Cerebellar & $\begin{array}{l}\text { Hsp70 production, suppressed PC loss, improved motor } \\
\text { function }\end{array}$ \\
\hline Watase et al., 2002 & Lithium & $154 \mathrm{Q} / 2 \mathrm{Q}$ & Dietary & $\begin{array}{l}\text { Improved motor coordination, learning, and memory. } \\
\text { Increased Dendritic branching in hippocampal pyramidal } \\
\text { neurons }\end{array}$ \\
\hline Perroud et al., 2013 & Lithium & $154 / 2 Q$ & Dietary & Increased metabolic processes, specifically higher purine levels \\
\hline lizuka et al., 2015 & Memantine & $154 \mathrm{Q} / 2 \mathrm{Q}$ & Dietary & $\begin{array}{l}\text { Attenuated PC loss and vagus motor neuron loss. Extended } \\
\text { life span and reduced weight loss }\end{array}$ \\
\hline
\end{tabular}


et al. (2014) review of WBV trials. The review states that there is insufficient evidence to support or negate if WBV can reduce symptoms in SCA among other diseases claiming more trials need to be performed with better methodological and reporting quality.

Hearst et al. (2014b) based on the neuroprotective role of chaperone HSPs known to modulate polyglutamine protein aggregation, explored the effects of focused laser light induced hyperthermia (HT) on HSP-mediated protection against ATXN1 toxicity in both cell culture model and transgenic mice. This study revealed that mild cerebellar HT stimulated the production of Hsp70 to a significant level and markedly suppressed the SCA 1 phenotype and PC loss as compared to sham-treated control animals (Hearst et al., 2014b). The nuclear inclusions in PCs stain positive for Hsp70 and Hsp40, ubiquitin and proteasomal subunits. Over expression of HDJ-2, an Hsp40 chaperone reduces protein aggregation (Cummings et al., 1998). Cummings et al. went on to find that overexpression of Hsp70 chaperone suppresses neuropathy and improves motor function in B05 mice (Cummings et al., 2001).

Lithium treatment has the potential to reduce SCA 1 symptoms in humans. A Watase et al. study showed that dietary lithium treatment resulted in improved motor coordination as well as learning and memory in 154Q/2Q mice. At 10 weeks of age, motor improvement was noted both in mice that received the treatment pre-symptomatically and post-symptomatically. Lithium treatment increased dendritic branching in mutant hippocampal pyramidal neurons (Watase et al., 2007). Perroud et al. also found that lithium treatment improved the motor coordination of $154 \mathrm{Q} / 2 \mathrm{Q}$ mice. Mice receiving lithium exhibited increased metabolic processes, particularly higher purine levels. Perroud et al. propose that purine metabolites might have a neuroprotective effect (Perroud et al., 2013). Lithium is involved in a large number of cell processes; it is not clear what combination is alleviating the symptoms. A human phase I trial of oral lithium was completed in 2010; results have yet to be published (NCT00683943).

Memantine, a low-affinity non-competitive N-methyl-daspartate (NMDA) receptor antagonist is a possible drug. Iizuka et al. orally administered memantine to $154 \mathrm{Q} / 2 \mathrm{Q}$ mice from 4 weeks old to death. Mice receiving the treatment lived longer and did not lose as much weight as typical 154Q/2Q mice. Mice receiving memantine had attenuated PC loss as well as motor neuron loss in the dorsal motor nucleus of the vagus. The study claims that these results exhibit that activation of extrasynaptic NMDA receptors lead to neuronal cell death in 154Q/2Q mice (Iizuka et al., 2015). However, the study fails to show the effect of memantine on SCA 1 symptoms is through its role as an NMDA antagonist. Memantine also affects the dopamine (Seeman et al., 2008), serotonin (Rammes et al., 2001), and acetyl choline receptors (Aracava et al., 2005) which would complicate its use as a SCA 1 therapy. Memantine has potential as a SCA 1 therapeutic but the mechanism of action needs to be better understood.

Glial cells have not received as much attention as neuronal pathology in SCA 1 studies, despite reports of gliosis in the brains of deceased SCA 1 patients (Genis et al., 1995; Gilman et al., 1996). In many neurological diseases, such as Amyotrophic Lateral Sclerosis and Parkinson's disease, astrocyte and microglia activation changes, including proinflammatory cytokine release, can reduce neuronal survival (Glass et al., 2010). Cvetanovic et al. observed hypertrophy of Bergmann glia, a sub-type of astrocyte that is located near Purkinje neurons, in 154Q/2Q mice using Glial Fibrillary Acidic Protein (GFAP). Hypertrophy was noticed in the presymptomatic period of the $154 \mathrm{Q} / 2 \mathrm{Q}$ model at 8 weeks old, and the GFAP staining increased with disease progression. Cvetanovic et al. also observed hypertrophy of microglia cells in $154 \mathrm{Q} / 2 \mathrm{Q}$ mice by staining for ionized calcium-binding adapter molecule 1 (Iba1). Like the Bergmann glia, microglia hypertrophy began at 8 weeks of age and increased with disease progression. Additionally, Cvetanovic et al. found glial activation occurs presymptomatically in B05 mice where only Purkinje neurons express ATXN1. Pro-inflammatory cytokine micro RNA levels increased alongside glial levels as well (Cvetanovic et al., 2015). Cvetanovic has recently received funding from the National Ataxia Foundation to test PLX3397, a drug that removes microglia from the brain without adverse effects in mice under laboratory conditions (Elmore et al., 2014), as a therapeutic.

\section{TREATMENTS USED IN OTHER SCA TYPES}

Two treatments currently being tested in other forms of SCA are worthy of mention, specifically Rhophylax, an IgG, and Dantrolene, a ryanodine-receptor inhibitor. Both therapies have the potential to be tested on SCA 1 as well.

It is believed that inflammation may contribute to neuronal dysfunction, although the pathophysiology is not known. Evert et al. (2001) found upregulation of mRNAs encoding metalloproteinase 2 (MMP-2), an endopeptidase matrix, the cytokine stromal cell-derived factor $1 \alpha(\mathrm{SDF} 1 \alpha)$, the transmembrane protein amyloid precursor protein, and the interleukin-1 receptor-related Fos-inducible transcript in SCA 3 mice. Immunohistochemical analysis of human SCA 3 brain tissue found increased expression of MMP- 2 and amyloid $\beta$ protein $(A \beta)$ in pontine neurons containing nuclear inclusions. Additionally, increased numbers of astrocytes and microglial cells were found in the pons of SCA 3 patients (Evert et al., 2001). In light of these results, a clinical trial is being initiated to administer intravenous immune globin (IVIG)- Rhophylax, an IgG, to SCA $1,2,3,6,10$, and 11 patients to observe how the drug effects SCA symptoms as well as nerve and motor function (NCT02287064). In the pilot for the clinical trial, three patients received three courses of IVIG-Rhophylax at 2 grams/ kilogram body weight over 5 days. Courses were 4 weeks apart. The patients in the pilot had SCA 3, SCA 5, or sporadic SCA. Results showed a 40\% reduction in SARA total score and 10-20\% average improvement in gait parameters. Patients improved the best after the third course and continued to improve until 28 days after the last infusion. Patients improvements declined by 56 days after the last infusion (Zesiewicz et al., 2014). 
Calcium-mediated neurodegeneration has attracted considerable attention in the past couple of decades (JimenezJimenez et al., 1996; Wojda et al., 2008); therefore a discussion on calcium-focused treatments for SCA 1 is warranted. Studies have shown SCA 1 model exhibiting down-regulation of proteins involved in PC calcium homeostasis, particularly Calbindin and Paravalbumin (Vig et al., 2000, 2001). Dantrolene has been tested on SCA 2 and SCA 3. Liu et al. found that mutant ataxin-2 facilitated inositol phosphate-induced $\mathrm{Ca}^{2+}$ release in cultured PC of a transgenic SCA 2 mouse model. Dantrolene blocked the $\mathrm{Ca}^{2+}$ release in vitro and, when given orally to mutant transgenic mice from 2 to 11 months old substantially reduced expression of SCA 2 (Liu et al., 2009). Chen et al. demonstrated that mutant ATXN3 associated with type 1 inositol 1,4,5-triphosphate receptor, an intracellular calcium release channel. They went on to demonstrate oral administration of dantrolene to SCA 3 transgenic mice stopped neuronal cell loss and improved motor performance, and stated dantrolene should be considered as a possible therapeutic for SCA 3 patients (Chen et al., 2008). Dantrolene should also be considered as a potential therapeutic for SCA 1.

\section{HURDLES}

At first glance, gene and cell therapies for SCA 1 seem to be straightforward. Gene therapy approaches involve the delivery of a transgene that can replace, silence, or inhibit the defective gene. Alternatively, the delivery of stem cells might replace the dying cell pool or provide a protective environment that would prevent these cells from dying. But in practice the process is more complex and a certain number of variables need to be controlled and optimized.

First, a route of delivery needs to be chosen. While peripheral administration (such as intravenous, intramuscular, or intranasal) sounds more appealing and less invasive, it raises several barriers. Higher dosages are needed to reach the same effect compared to a central delivery approach. Transduction of non-CNS tissues carries the risk of off-target effects. Finally, most gene therapy vectors lack the ability to cross the blood brain barrier.

Direct delivery to the CNS can be achieved via intraparenchymal injections to brain and spinal cord structures or via injections into the CSF (intrathecal or intraventricular). While these approaches offers the benefit of being more targeted, for SCA 1 a specific brain region may need to be chosen, such as

\section{REFERENCES}

Alvarez-Dolado, M., Pardal, R., Garcia-Verdugo, J. M., Fike, J. R., Lee, H. O., Pfeffer, K., et al. (2003). Fusion of bone-marrow-derived cells with Purkinje neurons, cardiomyocytes and hepatocytes. Nature 425, 968-973. doi: 10.1038 /nature02069

Alviña, K., and Khodakhah, K. (2010). The therapeutic mode of action of 4-aminopyridine in cerebellar ataxia. J. Neurosci. 30, 7258-7268. doi: 10.1523/JNEUROSCI.3582-09.2010 deep cerebellar nuclei or cerebellar hemispheres. Additionally, surgical techniques need to be developed and optimized to be more reproducible and accurate. While these methods are more invasive, direct delivery of viral vectors and stem cells into the CNS have proven safe and effective (Marks et al., 2010; Gutierrez et al., 2015).

Concerning stem cells, it is also very important to determine the factors behind successful grafts. Many studies do not characterize graft survival or the factors that allow these cells to slow the rate of disease progression. The description of graft characteristics and features would help predict the outcomes and help choose the optimal cell type for type of injection and brain region receiving the injection.

\section{CONCLUSION}

A wide variety of therapies for SCA 1 are being investigated to preserve PCs and slow disease onset and progression. While stem cell therapies are the ones that have currently reached the clinical trial stage, recent progress in gene and protein delivery appear to be equally promising for SCA 1 treatment. Mouse models, particularly the $154 \mathrm{Q} / 2 \mathrm{Q}$ mouse, provide a valuable model of the disease. However, the mechanism of action of polyQ-ATXN1 is not entirely understood and further research is needed to understand the disease process. Conceptually speaking, RNAi therapies, be they siRNA, shRNA, or miRNA-based, seem to be the most promising, since they deal directly with the root cause of the disease. All three RNAi options have been efficacious in SCA 1 models as well as models for other polyQ diseases. However, transducing a large majority of neurons throughout the brain remains a hurdle for gene therapy. Clinical trials will be necessary to determine which therapies or combinations of therapies will result in the best outcomes for patients.

\section{AUTHOR CONTRIBUTIONS}

JW is the primary author of the review. DO and AD edited the review and provided constructive criticism and approval. NB is an editor of the review and provided final approval.

\section{ACKNOWLEDGMENTS}

JW would like to thank the Boulis Lab and Emory University School of Medicine for their support in writing the review. 
Bürk, K., Bösch, S., Globas, C., Zühlke, C., Daum, I., Klockgether, T., et al. (2001). Executive dysfunction in spinocerebellar ataxia type 1. Eur. Neurol. 46, 43-48. doi: $10.1159 / 000050755$

Burright, E. N., Clark, H. B., Servadio, A., Matilla, T., Feddersen, R. M., Yunis, W. S., et al. (1995). SCA1 transgenic mice: a model for neurodegeneration caused by an expanded CAG trinucleotide repeat. Cell 82, 937-948. doi: 10.1016/0092-8674(95)90273-2

Chang, Y. K., Chen, M. H., Chiang, Y. H., Chen, Y. F., Ma, W. H., Tseng, C. Y., et al. (2011). Mesenchymal stem cell transplantation ameliorates motor function deterioration of spinocerebellar ataxia by rescuing cerebellar Purkinje cells. J. Biomed. Sci. 18:54. doi: 10.1186/1423-0127-18-54

Chen, H. K., Fernandez-Funez, P., Acevedo, S. F., Lam, Y. C., Kaytor, M. D., Fernandez, M. H., et al. (2003). Interaction of Akt-phosphorylated ataxin-1 with 14-3-3 mediates neurodegeneration in spinocerebellar ataxia type 1. Cell 113, 457-468. doi: 10.1016/S0092-8674(03)00349-0

Chen, K. A., Cruz, P. E., Lanuto, D. J., Flotte, T. R., Borchelt, D. R., Srivastava, A., et al. (2011). Cellular fusion for gene delivery to SCA1 affected Purkinje neurons. Mol. Cell. Neurosci. 47, 61-70. doi: 10.1016/j.mcn.2011.03.003

Chen, X., Tang, T. S., Tu, H., Nelson, O., Pook, M., Hammer, R., et al. (2008). Deranged calcium signaling and neurodegeneration in spinocerebellar ataxia type 3. J. Neurosci. 28, 12713-12724. doi: 10.1523/JNEUROSCI.3909-08.2008

Chintawar, S., Hourez, R., Ravella, A., Gall, D., Orduz, D., Rai, M., et al. (2009). Grafting neural precursor cells promotes functional recovery in an SCA1 mouse model. J. Neurosci. 29, 13126-13135. doi: 10.1523/JNEUROSCI.0647-09.2009

Clark, H. B., Burright, E. N., Yunis, W. S., Larson, S., Wilcox, C., Hartman, B., et al. (1997). Purkinje cell expression of a mutant allele of SCA1 in transgenic mice leads to disparate effects on motor behaviors, followed by a progressive cerebellar dysfunction and histological alterations. J. Neurosci. 17, 7385-7395.

Cummings, C. J., Mancini, M. A., Antalffy, B., DeFranco, D. B., Orr, H. T., and Zoghbi, H. Y. (1998). Chaperone suppression of aggregation and altered subcellular proteasome localization imply protein misfolding in SCA1. Nat. Genet. 19, 148-154. doi: 10.1038/502

Cummings, C. J., Sun, Y., Opal, P., Antalffy, B., Mestril, R., Orr, H. T., et al. (2001). Over-expression of inducible HSP70 chaperone suppresses neuropathology and improves motor function in SCA1 mice. Hum. Mol. Genet. 10, 1511-1518. doi: $10.1093 / \mathrm{hmg} / 10.14 .1511$

Cvetanovic, M., Ingram, M., Orr, H., and Opal, P. (2015). Early activation of microglia and astrocytes in mouse models of spinocerebellar ataxia type 1 . Neuroscience 289, 289-299. doi: 10.1016/j.neuroscience.2015.01.003

Cvetanovic, M., Patel, J. M., Marti, H. H., Kini, A. R., and Opal, P. (2011). Vascular endothelial growth factor ameliorates the ataxic phenotype in a mouse model of spinocerebellar ataxia type 1. Nat. Med. 17, 1445-1447. doi: 10.1038/nm.2494

Cvetanovic, M., Rooney, R. J., Garcia, J. J., Toporovskaya, N., Zoghbi, H. Y., and Opal, P. (2007). The role of LANP and ataxin 1 in E4F-mediated transcriptional repression. EMBO Rep. 8, 671-677. doi: 10.1038/sj.embor.7400983

Davidson, B. L., and Paulson, H. L. (2004). Molecular medicine for the brain: silencing of disease genes with RNA interference. Lancet Neurol. 3, 145-149. doi: 10.1016/S1474-4422(04)00678-7

de Chiara, C., Giannini, C., Adinolfi, S., de Boer, J., Guida, S., Ramos, A., et al. (2003). The AXH module: an independently folded domain common to ataxin1 and HBP1. FEBS Lett. 551, 107-112. doi: 10.1016/S0014-5793(03)00818-4

Dongmei, H., Jing, L., Mei, X., Ling, Z., Hongmin, Y., Zhidong, W., et al. (2011). Clinical analysis of the treatment of spinocerebellar ataxia and multiple system atrophy-cerebellar type with umbilical cord mesenchymal stromal cells. Cytotherapy 13, 913-917. doi: 10.3109/14653249.2011.579958

Elmore, M. R., Najafi, A. R., Koike, M. A., Dagher, N. N., Spangenberg, E. E., Rice, R. A., et al. (2014). Colony-stimulating factor 1 receptor signaling is necessary for microglia viability, unmasking a microglia progenitor cell in the adult brain. Neuron 82, 380-397. doi: 10.1016/j.neuron.2014.02.040

Emamian, E. S., Kaytor, M. D., Duvick, L. A., Zu, T., Tousey, S. K., Zoghbi, H. Y., et al. (2003). Serine 776 of ataxin-1 is critical for polyglutamine-induced disease in SCA1 transgenic mice. Neuron 38, 375-387. doi: 10.1016/S08966273(03)00258-7

Evert, B. O., Vogt, I. R., Kindermann, C., Ozimek, L., de Vos, R. A. I., Brunt, E. R. P., et al. (2001). Inflammatory genes are upregulated in expanded ataxin-3expressing cell lines and spinocerebellar ataxia type 3 brains. J. Neurosci. 21, 5389-5396.
Fernandez-Funez, P., Nino-Rosales, M. L., de Gouyon, B., She, W. C., Luchak, J. M., Martinez, P., et al. (2000). Identification of genes that modify ataxin-1induced neurodegeneration. Nature 408, 101-106. doi: 10.1038/35040584

Gatchel, J. R., Watase, K., Thaller, C., Carson, J. P., Jafar-Nejad, P., Shaw, C., et al. (2008). The insulin-like growth factor pathway is altered in spinocerebellar ataxia type 1 and type 7. Proc. Natl. Acad. Sci. U.S.A. 105, 1291-1296. doi: 10.1073/pnas.0711257105

Genis, D., Matilla, T., Volpini, V., Rosell, J., Dávalos, A., Ferrer, I., et al. (1995). Clinical, neuropathologic, and genetic studies of a large spinocerebellar ataxia type 1 (SCA1) kindred: (CAG)n expansion and early premonitory signs and symptoms. Neurology 45, 24-30. doi: 10.1212/WNL.45.1.24

Gilman, S., Sima, A. A., Junck, L., Kluin, K. J., Koeppe, R. A., Lohman, M. E., et al. (1996). Spinocerebellar ataxia type 1 with multiple system degeneration and glial cytoplasmic inclusions. Ann. Neurol. 39, 241-255. doi: 10.1002/ana.410390214

Glass, C. K., Saijo, K., Winner, B., Marchetto, M. C., and Gage, F. H. (2010). Mechanisms underlying inflammation in neurodegeneration. Cell 140, 918-934. doi: 10.1016/j.cell.2010.02.016

Goold, R., Hubank, M., Hunt, A., Holton, J., Menon, R. P., Revesz, T., et al. (2007). Down-regulation of the dopamine receptor D2 in mice lacking ataxin 1. Hum. Mol. Genet. 16, 2122-2134. doi: 10.1093/hmg/ddm162

Grimm, D., Streetz, K. L., Jopling, C. L., Storm, T. A., Pandey, K., Davis, C. R., et al. (2006). Fatality in mice due to oversaturation of cellular microRNA/short hairpin RNA pathways. Nature 441, 537-541. doi: 10.1038/nature04791

Gutierrez, J., Moreton, C. L., Lamanna, J. J., Schapiro, R., Grin, N., Hurtig, C. V., et al. (2015). 203 Understanding cell migration after direct transplantation into the spinal cord: a tool to determine the optimal transplantation volume. Neurosurgery 62(Suppl. 1), 234. doi: 10.1227/01.neu.0000467124. 38322.47

Haas, C. T., Turbanski, S., Kessler, K., and Schmidtbleicher, D. (2006). The effects of random whole-body-vibration on motor symptoms in Parkinson's disease. NeuroRehabilitation 21, 29-36. doi: 10.1007/3-540-36741-1_8

Harper, S. Q., Staber, P. D., He, X., Eliason, S. L., Martins, I. H., Mao, Q., et al. (2005). RNA interference improves motor and neuropathological abnormalities in a Huntington's disease mouse model. Proc. Natl. Acad. Sci. U.S.A. 102, 5820-5825. doi: 10.1073/pnas.0501507102

Hearst, S. M., Shao, Q., Lopez, M., Raucher, D., and Vig, P. J. (2014a). The design and delivery of a PKA inhibitory polypeptide to treat SCA1. J. Neurochem. 131, 101-114. doi: $10.1111 /$ jnc. 12782

Hearst, S. M., Shao, Q., Lopez, M., Raucher, D., and Vig, P. J. (2014b). Focused cerebellar laser light induced hyperthermia improves symptoms and pathology of polyglutamine disease SCA1 in a mouse model. Cerebellum 13, 596-606. doi: 10.1007/s12311-014-0576-1

Hong, S., Ka, S., Kim, S., Park, Y., and Kang, S. (2003). p80 coilin, a coiled body-specific protein, interacts with ataxin-1, the SCA1 gene product. Biochim. Biophys. Acta 1638, 35-42. doi: 10.1016/S0925-4439(03)00038-3

Hourez, R., Servais, L., Orduz, D., Gall, D., Millard, I., de Kerchove d'Exaerde, A., et al. (2011). Aminopyridines correct early dysfunction and delay neurodegeneration in a mouse model of spinocerebellar ataxia type 1. J. Neurosci. 31, 11795-11807. doi: 10.1523/JNEUROSCI.0905-11.2011

Huang, C.-C., Tseng, T.-L., Huang, W.-C., Chung, Y.-H., Chuang, H.-L., and Wu, J.-H. (2014). Whole-body vibration training effect on physical performance and obesity in mice. Int. J. Med. Sci. 11, 1218-1227. doi: 10.7150/ijms.9975

Iizuka, A., Nakamura, K., and Hirai, H. (2015). Long-term oral administration of the NMDA receptor antagonist memantine extends life span in spinocerebellar ataxia type 1 knock-in mice. Neurosci. Lett. 592, 37-41. doi: 10.1016/j.neulet.2015.02.055

Jayadev, S., and Bird, T. D. (2013). Hereditary ataxias: overview. Genet. Med. 15, 673-683. doi: 10.1038/gim.2013.28

Jimenez-Jimenez, F. J., García-Ruiz, P. J., and de Bustos, F. (1996). Calcium, neuronal death and neurological disease. Rev. Neurol. 24, 1199-1209.

Jin, J. L., Liu, Z., Lu, Z. J., Guan, D. N., Wang, C., Chen, Z. B., et al. (2013). Safety and efficacy of umbilical cord mesenchymal stem cell therapy in hereditary spinocerebellar ataxia. Curr. Neurovasc. Res. 10, 11-20. doi: $10.2174 / 156720213804805936$

Jones, J., Jaramillo-Merchán, J., Bueno, C., Pastor, D., Viso-León, M., and Martinez, S. (2010). Mesenchymal stem cells rescue Purkinje cells and improve motor 
functions in a mouse model of cerebellar ataxia. Neurobiol. Dis. 40, 415-423. doi: 10.1016/j.nbd.2010.07.001

Jorgensen, N. D., Andresen, J. M., Lagalwar, S., Armstrong, B., Stevens, S., Byam, C. E., et al. (2009). Phosphorylation of ATXN1 at Ser776 in the cerebellum. J. Neurochem. 110, 675-686. doi: 10.1111/j.1471-4159.2009.06164.x

Kang, S., and Hong, S. (2009). Molecular pathogenesis of spinocerebellar ataxia type 1 disease. Mol. Cells 27, 621-627. doi: 10.1007/s10059-009-0095-y

Kang, S., Jaworski, A., Ohshima, K., and Wells, R. D. (1995). Expansion and deletion of CTG repeats from human disease genes are determined by the direction of replication in E. coli. Nat. Genet. 10, 213-218. doi: 10.1038/ng0695-213

Karagianni, P., and Wong, J. (2007). HDAC3: taking the SMRT-N-CoRrect road to repression. Oncogene 26, 5439-5449. doi: 10.1038/sj.onc.1210612

Kaut, O., Jacobi, H., Coch, C., Prochnicki, A., Minnerop, M., Klockgether, T., et al. (2014). A randomized pilot study of stochastic vibration therapy in spinocerebellar ataxia. Cerebellum 13, 237-242. doi: 10.1007/s12311-0130532-5

Keiser, M. S., Boudreau, R. L., and Davidson, B. L. (2014). Broad therapeutic benefit after RNAi expression vector delivery to deep cerebellar nuclei: implications for spinocerebellar ataxia type 1 therapy. Mol. Ther. 22, 588-595. doi: $10.1038 / \mathrm{mt} .2013 .279$

Keiser, M. S., Geoghegan, J. C., Boudreau, R. L., Lennox, K. A., and Davidson, B. L. (2013). RNAi or overexpression: alternative therapies for Spinocerebellar Ataxia Type 1. Neurobiol. Dis. 56, 6-13. doi: 10.1016/j.nbd.2013.04.003

Keiser, M. S., Kordower, J. H., Gonzalez-Alegre, P., and Davidson, B. L. (2015). Broad distribution of ataxin 1 silencing in rhesus cerebella for spinocerebellar ataxia type 1 therapy. Brain 138(Pt 12), 3555-3566. doi: 10.1093/brain/awv292

Kirsch, G. E., and Narahashi, T. (1978). 3,4-diaminopyridine. A potent new potassium channel blocker. Biophys. J. 22, 507-512. doi: 10.1016/S00063495(78)85503-9

Lam, J. K., Chow, M. Y., Zhang, Y., and Leung, S. W. (2015). siRNA versus miRNA as therapeutics for gene silencing. Mol. Ther. Nucleic Acids 4, e252. doi: 10.1038/mtna.2015.23

Lam, Y. C., Bowman, A. B., Jafar-Nejad, P., Lim, J., Richman, R., Fryer, J. D., et al. (2006). ATAXIN-1 interacts with the repressor Capicua in its native complex to cause SCA1 neuropathology. Cell 127, 1335-1347. doi: 10.1016/j.cell.2006.11.038

Lee, S., Hong, S., and Kang, S. (2008). The ubiquitin-conjugating enzyme UbcH6 regulates the transcriptional repression activity of the SCA1 gene product ataxin-1. Biochem. Biophys. Res. Commun. 372, 735-740. doi: 10.1016/j.bbrc.2008.05.125

Lee, Y., Samaco, R. C., Gatchel, J. R., Thaller, C., Orr, H. T., and Zoghbi, H. Y. (2008). miR-19, miR-101 and miR-130 co-regulate ATXN1 levels to potentially modulate SCA1 pathogenesis. Nat. Neurosci. 11, 1137-1139. doi: $10.1038 / \mathrm{nn} .2183$

Lim, J., Crespo-Barreto, J., Jafar-Nejad, P., Bowman, A. B., Richman, R., Hill, D. E., et al. (2008). Opposing effects of polyglutamine expansion on native protein complexes contribute to SCA1. Nature 452, 713-718. doi: 10.1038/nature06731

Lin, X., Antalffy, B., Kang, D., Orr, H. T., and Zoghbi, H. Y. (2000). Polyglutamine expansion down-regulates specific neuronal genes before pathologic changes in SCA1. Nat. Neurosci. 3, 157-163. doi: 10.1038/72101

Liu, J., Tang, T. S., Tu, H., Nelson, O., Herndon, E., Huynh, D. P., et al. (2009). Deranged calcium signaling and neurodegeneration in spinocerebellar ataxia type 2. J. Neurosci. 29, 9148-9162. doi: 10.1523/JNEUROSCI.0660-09.2009

Marks, W. J. Jr., Bartus, R. T., Siffert, J., Davis, C. S., Lozano, A., Boulis, N., et al. (2010). Gene delivery of AAV2-neurturin for Parkinson's disease: a double-blind, randomised, controlled trial. Lancet Neurol. 9, 1164-1172. doi: 10.1016/S1474-4422(10)70254-4

Matilla, T., Volpini, V., Genis, D., Rosell, J., Corral, J., Davalos, A., et al. (1993). Presymptomatic analysis of spinocerebellar ataxia type 1 (SCA1) via the expansion of the SCA1 CAG-repeat in a large pedigree displaying anticipation and parental male bias. Hum. Mol. Genet. 2, 2123-2128. doi: 10.1093/hmg/2.12.2123

Matsuura, S., Shuvaev, A. N., Iizuka, A., Nakamura, K., and Hirai, H. (2014). Mesenchymal stem cells ameliorate cerebellar pathology in a mouse model of spinocerebellar ataxia type 1. Cerebellum 13, 323-330. doi: 10.1007/s12311-0130536-1
Miller, V. M., Xia, H., Marrs, G. L., Gouvion, C. M., Lee, G., Davidson, B. L., et al. (2003). Allele-specific silencing of dominant disease genes. Proc. Natl. Acad. Sci. U.S.A. 100, 7195-7200. doi: 10.1073/pnas.1231012100

Monteys, A. M., Wilson, M. J., Boudreau, R. L., Spengler, R. M., and Davidson, B. L. (2015). Artificial miRNAs targeting mutant huntingtin show preferential silencing in vitro and in vivo. Mol. Ther. Nucleic Acids 4, e234. doi: 10.1038/mtna.2015.7

Oberdick, J., Smeyne, R. J., Mann, J. R., Zackson, S., and Morgan, J. I. (1990). A promoter that drives transgene expression in cerebellar Purkinje and retinal bipolar neurons. Science 248, 223-226. doi: 10.1126/science.2109351

Perroud, B., Jafar-Nejad, P., Wikoff, W. R., Gatchel, J. R., Wang, L., Barupal, D. K., et al. (2013). Pharmacometabolomic signature of ataxia SCA1 mouse model and lithium effects. PLoS ONE 8:e70610. doi: 10.1371/journal.pone.0070610

Ramachandran, P. S., Bhattarai, S., Singh, P., Boudreau, R. L., Thompson, S., Laspada, A. R., et al. (2014). RNA interference-based therapy for spinocerebellar ataxia type 7 retinal degeneration. PLOS ONE 9:e95362. doi: 10.1371/journal.pone.0095362

Rammes, G., Rupprecht, R., Ferrari, U., Zieglgansberger, W., and Parsons, C. G. (2001). The N-methyl-D-aspartate receptor channel blockers memantine, MRZ 2/579 and other amino-alkyl-cyclohexanes antagonise 5-HT(3) receptor currents in cultured HEK-293 and N1E-115 cell systems in a noncompetitive manner. Neurosci. Lett. 306, 81-84. doi: 10.1016/S0304-3940(01) 01872-9

Rodriguez-Lebron, E., Costa Mdo, C., Luna-Cancalon, K., Peron, T. M., Fischer, S., Boudreau, R. L., et al. (2013). Silencing mutant ATXN3 expression resolves molecular phenotypes in SCA3 transgenic mice. Mol. Ther. 21, 1909-1918. doi: $10.1038 / \mathrm{mt} .2013 .152$

Schols, L., Bauer, P., Schmidt, T., Schulte, T., and Riess, O. (2004). Autosomal dominant cerebellar ataxias: clinical features, genetics, and pathogenesis. Lancet Neurol. 3, 291-304. doi: 10.1016/S1474-4422(04) 00737-9

Seeman, P., Caruso, C., and Lasaga, M. (2008). Memantine agonist action at dopamine D2High receptors. Synapse 62, 149-153. doi: 10.1002/syn. 20472

Servadio, A., Koshy, B., Armstrong, D., Antalffy, B., Orr, H. T., and Zoghbi, H. Y. (1995). Expression analysis of the ataxin-1 protein in tissues from normal and spinocerebellar ataxia type 1 individuals. Nat. Genet. 10, 94-98. doi: $10.1038 /$ ng0595-94

Subramony, S. H., and Ashizawa, T. (1993). "Spinocerebellar ataxia type 1," in GeneReviews(R), eds R. A. Pagon, M. P. Adam, H. H. Ardinger, S. E. Wallace, A. Amemiya, L. J. H. Bean, T. D. Bird, C.-T. Fong, H. C. Mefford, R. J. H. Smith, and K. Stephens (Seattle, WA: University of Washington).

Vandaele, S., Nordquist, D. T., Feddersen, R. M., Tretjakoff, I., Peterson, A. C., and Orr, H. T. (1991). Purkinje cell protein-2 regulatory regions and transgene expression in cerebellar compartments. Genes Dev. 5, 1136-1148. doi: 10.1101/gad.5.7.1136

Venkatraman, A., Hu, Y. S., Didonna, A., Cvetanovic, M., Krbanjevic, A., Bilesimo, P., et al. (2014). The histone deacetylase HDAC3 is essential for Purkinje cell function, potentially complicating the use of HDAC inhibitors in SCA1. Hum. Mol. Genet. 23, 3733-3745. doi: 10.1093/hmg/ddu081

Vierra-Green, C. A., Orr, H. T., Zoghbi, H. Y., and Ferrington, D. A. (2005). Identification of a novel phosphorylation site in ataxin-1. Biochim. Biophys. Acta 1744, 11-18. doi: 10.1016/j.bbamcr.2004.10.012

Vig, P. J., Subramony, S. H., and McDaniel, D. O. (2001). Calcium homeostasis and spinocerebellar ataxia-1 (SCA-1). Brain Res. Bull. 56, 221-225. doi: 10.1016/S0361-9230(01)00595-0

Vig, P. J., Subramony, S. H., Qin, Z., McDaniel, D. O., and Fratkin, J. D. (2000). Relationship between ataxin-1 nuclear inclusions and Purkinje cell specific proteins in SCA-1 transgenic mice. J. Neurol. Sci. 174, 100-110. doi: 10.1016/S0022-510X(00)00262-8

Watase, K., Gatchel, J. R., Sun, Y., Emamian, E., Atkinson, R., Richman, R., et al. (2007). Lithium therapy improves neurological function and hippocampal dendritic arborization in a spinocerebellar ataxia type 1 mouse model. PLoS Med. 4:e182. doi: 10.1371/journal.pmed.0040182

Watase, K., Weeber, E. J., Xu, B., Antalffy, B., Yuva-Paylor, L., Hashimoto, $\mathrm{K}$., et al. (2002). A long CAG repeat in the mouse Scal locus replicates SCA1 features and reveals the impact of protein solubility on selective 
neurodegeneration. Neuron 34, 905-919. doi: 10.1016/S0896-6273(02) 00733-X

Weimann, J. M., Charlton, C. A., Brazelton, T. R., Hackman, R. C., and Blau, H. M. (2003). Contribution of transplanted bone marrow cells to Purkinje neurons in human adult brains. Proc. Natl. Acad. Sci. U.S.A. 100, 2088-2093. doi: 10.1073/pnas.0337659100

Whaley, N. R., Fujioka, S., and Wszolek, Z. K. (2011). Autosomal dominant cerebellar ataxia type I: a review of the phenotypic and genotypic characteristics. Orphanet J. Rare Dis. 6:33. doi: 10.1186/1750-1172-6-33

Wojda, U., Salinska, E., and Kuznicki, J. (2008). Calcium ions in neuronal degeneration. IUBMB Life 60, 575-590. doi: 10.1002/iub.91

Xia, H., Mao, Q., Eliason, S. L., Harper, S. Q., Martins, I. H., Orr, H. T., et al. (2004). RNAi suppresses polyglutamine-induced neurodegeneration in a model of spinocerebellar ataxia. Nat. Med. 10, 816-820. doi: 10.1038/nm1076

Xia, H., Mao, Q., Paulson, H. L., and Davidson, B. L. (2002). siRNA-mediated gene silencing in vitro and in vivo. Nat. Biotechnol. 20, 1006-1010. doi: $10.1038 /$ nbt739

Yang, S. H., Cheng, P. H., Banta, H., Piotrowska-Nitsche, K., Yang, J. J., Cheng, E. C., et al. (2008). Towards a transgenic model of Huntington's disease in a non-human primate. Nature 453, 921-924. doi: 10.1038/nature06975

Yue, S., Serra, H. G., Zoghbi, H. Y., and Orr, H. T. (2001). The spinocerebellar ataxia type 1 protein, ataxin-1, has RNA-binding activity that is inversely affected by the length of its polyglutamine tract. Hum. Mol. Genet. 10, 25-30. doi: $10.1093 / \mathrm{hmg} / 10.1 .25$
Zesiewicz, T., Vu, T., Sullivan, K., Gooch, C., Jahan, I., Ward, C., et al. (2014). Treatment of Spinocerebellar Ataxia with Intravenous Immune Globulin (IVIG) (P6.052). Neurology 82(10 Suppl.).

Zoghbi, H. Y., Pollack, M. S., Lyons, L. A., Ferrell, R. E., Daiger, S. P., and Beaudet, A. L. (1988). Spinocerebellar ataxia: variable age of onset and linkage to human leukocyte antigen in a large kindred. Ann. Neurol. 23, 580-584. doi: 10.1002/ana.410230609

Conflict of Interest Statement: NB is a paid consultant for Agilis, MRI Interventions, Voyager, Oxford Biomedica, Q Therapeutics and Neuralstem Inc. $\mathrm{He}$ is a founder of Switch Bio Holdings and former employee of Above and Beyond LLC up to December 1st 2015.

The other authors declare that the research was conducted in the absence of any commercial or financial relationships that could be construed as a potential conflict of interest.

Copyright (c) 2016 Wagner, O'Connor, Donsante and Boulis. This is an openaccess article distributed under the terms of the Creative Commons Attribution License (CC BY). The use, distribution or reproduction in other forums is permitted, provided the original author(s) or licensor are credited and that the original publication in this journal is cited, in accordance with accepted academic practice. No use, distribution or reproduction is permitted which does not comply with these terms. 